\title{
The rate of visual field loss in untreated primary open angle glaucoma
}

Reduction of visual field is the functional manifestation of the loss of optic nerve fibres which occurs in primary open angle glaucoma. Visual field measurement is the commonest test of visual function used to follow the progress of the disease and to assess the need to introduce or change treatment. The rate of decay of field in patients receiving treatment was estimated by Smith' at approximately $-3 \%$ per annum, starting from $70 \%$ of residual field. He extrapolated that it might take about 30 years to progress from early visual field defects to complete loss of field. Treated patients therefore seem to deteriorate only very slowly. It has been observed that the course of this deterioration varies; some eyes show episodic or curvilinear field loss with time rather than gradual linear deterioration. $^{2}$ These fluctuations are, however, relatively brief and would not invalidate a linear expression of average rate of decay over several years. There is similarly very slow progression from ocular hypertension without field loss to glaucoma with field defects. Goldmann ${ }^{3}$ described Leydhecker's finding that the average interval for this is 18 years but the progression is faster with higher levels of intraocular pressure. ${ }^{456}$

The rate of field decay in untreated disease after clinically identifiable defects have appeared is, however, unknown. We have observed eyes with minor visual field changes progress to blindness in less than 5 years when patients stopped treatment, defaulted from follow up, and returned only when they noticed loss of vision. A further indication that there may be more rapid deterioration than is generally recognised comes from the comparison of different treatment strategies in the Glasgow trial of early trabeculectomy for primary open angle glaucoma. ${ }^{78}$ In this study some patients showed a very rapid rate of visual field loss during an initial trial of medical treatment and trabeculectomy halted the deterioration. We therefore set out to devise a method of measuring the rate of visual field decay in untreated primary open angle glaucoma and compare it with the rate of change under different forms of treatment.

\section{Methods}

The average time taken to progress from the earliest identifiable stages of glaucomatous visual field loss to the end stage of the disease, near blindness, was derived from comparison of the age at diagnosis of patients who presented with mild field loss, with those who presented when the visual field had almost been extinguished. The difference in average age at. presentation for the two stages of the disease provides an estimate of the average rate of progression of field loss before diagnosis and treatment. Visual field changes were classified in a fashion similar to that of Jay and Murray ${ }^{7}$ and divided into five stages (Table 1). For the purpose of this study, early disease was defined as stage 1 field change and end stage disease was defined as stages 4 or 5 (absolute scotomas within $5^{\circ}$ of fixation).

Patients in the study were identified from those who attended the Tennent Institute of Ophthalmology or Glasgow Eye Infirmary with primary open glaucoma. The following information for the time of diagnosis was noted
Table 1 Classification of visual field loss

\begin{tabular}{ll}
\hline Stage & Field change \\
\hline 1 & $\begin{array}{l}\text { Mild relative defects in glaucomatous pattern to Tubingen oculus } \\
1 \cdot 0 / 10 \text { asb (Goldmann I-2e) or Friedmann analyser at threshold for } \\
\text { age of subject }\end{array}$ \\
& $\begin{array}{l}\text { Absolute scotomas outside } 10^{\circ} \text { of fixation to Tubingen oculus } \\
\text { stimulus } 1 \cdot 0 / 00 \text { asb (Goldmann } \mathrm{I}-4 \mathrm{e} \text { ) or Friedmann analyser at }\end{array}$ \\
maximum & As stage 2 but encroaching between $10^{\circ}$ and $5^{\circ}$ from fixation \\
3 & As stage 2 but within $5^{\circ}$ of fixation in one to three quadrants \\
4 & As stage 2 but within $5^{\circ}$ of fixation in all quadrants \\
\hline
\end{tabular}

from the case record: age, sex, corrected Snellen acuity, maximum untreated intraocular pressure (applanation), gonioscopy, slit-lamp microscopy, fundus appearance, and visual field. Details of general health and family history were also recorded. Patients were excluded for the following reasons: inadequate information in the case record, visual acuity less than $6 / 18$, untreated intraocular pressure below 21 $\mathrm{mm} \mathrm{Hg}$, visual field test not performed within 1 month of diagnosis. Eyes with a history of disorders other than glaucoma which might affect visual field or intraocular pressure (commonly uveitis, retinal detachment, or ocular trauma) were also excluded.

Where both eyes of a patient qualified for inclusion, only the one with worse field loss was used for analysis. The difference in mean age at presentation with early (stage 1) and end stage (stages 4 and 5) field loss was calculated and further age analysis performed for subgroups at different levels of untreated intraocular pressure at diagnosis - namely, 21-25 $\mathrm{mm} \mathrm{Hg}, 26-30 \mathrm{~mm} \mathrm{Hg}$, over $30 \mathrm{~mm} \mathrm{Hg}$, etc. The estimated rate of field loss in untreated disease was then compared with the average rate of loss during treatment in the Glasgow trial of early trabeculectomy. ${ }^{8}$ Separate data were available for first year of medical therapy, conventional sequence of medical therapy followed by trabeculectomy where necessary, and after early or delayed trabeculectomy. The rate of

Table 2 Difference in mean age at presentation between early disease and end stage disease. This indicates the probable average time taken for untreated primary open angle glaucoma to progress to blindness after early field defects appear. Progress is more rapid at higher levels of intraocular pressure

\begin{tabular}{llllll}
\hline \multirow{2}{*}{$\begin{array}{l}\text { Untreated IOP } \\
\text { at diagnosis } \\
(m m H g)\end{array}$} & $\begin{array}{l}\text { Mean age } \\
\text { Early disease } \\
(n)(S E)\end{array}$ & $\begin{array}{l}\text { End stage } \\
(n)(S E)\end{array}$ & $\begin{array}{l}\text { Difference in } \\
\text { years }(S E)\end{array}$ & p Value \\
\hline $21-25$ & $58 \cdot 4(23)(1 \cdot 9)$ & $72 \cdot 8(9)(1 \cdot 1)$ & $14 \cdot 4(2 \cdot 2)$ & $<0.00001$ \\
$26-30$ & $64 \cdot 2(31)(2 \cdot 0)$ & $70 \cdot 7(22)(2 \cdot 1)$ & $6 \cdot 5(2 \cdot 9)$ & 0.029 \\
$>30$ & $63 \cdot 8(20)(1 \cdot 8)$ & $66.7(72)(1 \cdot 1)$ & $2 \cdot 9(2 \cdot 1)$ & 0.17 \\
\hline
\end{tabular}

Table 3 Data as in Table 2 but stratified by minimum intraocular pressure at diagnosis. See text for statistical analysis of difference between rows

\begin{tabular}{|c|c|c|c|c|}
\hline \multirow{2}{*}{$\begin{array}{l}\text { Untreated IOP } \\
\text { at diagnosis } \\
\text { (mm Hg })\end{array}$} & \multicolumn{2}{|l|}{ Mean age } & \multirow[b]{2}{*}{$\begin{array}{l}\text { Difference in } \\
\text { years }(S E)\end{array}$} & \multirow[b]{2}{*}{$p$ Value } \\
\hline & $\begin{array}{l}\text { Early disease } \\
(n)(S E)\end{array}$ & $\begin{array}{l}\text { End stage } \\
(n)(S E)\end{array}$ & & \\
\hline $\begin{array}{l}>20 \\
>25 \\
>30\end{array}$ & $\begin{array}{l}62 \cdot 2(74)(1 \cdot 2) \\
64 \cdot 0(51)(1.4) \\
63 \cdot 8(20)(1.8)\end{array}$ & $\begin{array}{l}68 \cdot 1(103)(0 \cdot 9) \\
67 \cdot 6(94)(1 \cdot 0) \\
66 \cdot 7(72)(1 \cdot 1)\end{array}$ & $\begin{array}{l}5 \cdot 9(1 \cdot 5) \\
3 \cdot 6(1 \cdot 7) \\
2 \cdot 9(2 \cdot 1)\end{array}$ & $\begin{array}{l}0.0001 \\
0.035 \\
0.17\end{array}$ \\
\hline
\end{tabular}


Table 4 Comparison of estimated time for primary open angle glaucoma to progress from first detectable field loss to end stage disease. The effect of treatment and the disadvantage of unsatisfactory treatment can be seen.

Untreated ${ }^{\star}$ (present study)

Unsatisfactory treatment ${ }^{\star} ;$ Jay and Allen

Unsatisfactory treatment ${ }^{\star}$; Jay and A

Optimum treatment
Treatment trial; Smith $^{1}$

3.6 years

10 years

38 years

*Intraocular pressure at diagnosis $>25 \mathrm{~mm} \mathrm{Hg}$

field decay was derived from changes in mean visual field stage of subgroups in this study which employed the same five stage visual field classification described above.

Statistical comparisons of the ages of the patients presenting with early and end stage disease were performed by the two sample $t$ tests using $95 \%$ confidence interval.

\section{Results}

We identified 177 patients with eyes which presented with visual field in stages 1 or 4 and 5 , with sufficient information for analysis. Details of mean age at diagnosis for early disease and terminal disease are set out in Tables 2 and 3. Table 2 gives data for intraocular pressure at diagnosis in separate bands, $21-25 \mathrm{~mm} \mathrm{Hg}, 26-30 \mathrm{~mm} \mathrm{Hg}$, and $>30 \mathrm{~mm} \mathrm{Hg}$. In all these subgroups except for eyes with pressure $>30 \mathrm{~mm} \mathrm{Hg}$ the mean age of presentation with early disease was statistically distinct from that with end stage disease (see Tables 2 and 3 ). The difference varied from 3.6 years for eyes with intraocular pressure $>25 \mathrm{~mm} \mathrm{Hg}$ (Table 3) to 14.4 years for pressures between 21 and $25 \mathrm{~mm} \mathrm{Hg}$ (Table 2). The 2.9 year difference for eyes with intraocular pressure $>30 \mathrm{~mm} \mathrm{Hg}$ is too short to be confirmed on statistical analysis of the numbers available.

There is a trend for eyes with higher intraocular pressures to have more rapidly progressive disease in both Tables 2 and 3. This trend was examined statistically by testing the standard error of the differences between the rows in each table. Thus, in Table 2 the 14.4 year interval for disease progression in eyes with pressures between 21 and $25 \mathrm{~mm} \mathrm{Hg}$ is significantly different from the 2.9 year interval for pressures $>30 \mathrm{~mm} \mathrm{Hg}(\mathrm{p}<0.001)$ and from the 6.5 year interval for eyes between $26 \mathrm{~mm} \mathrm{Hg}$ and $30 \mathrm{~mm} \mathrm{Hg}$ $(p<0.001)$, but the 2.9 year interval and the 6.5 year interval could not be distinguished statistically $(p=0.317)$. A similar examination of Table 3 shows the 5.9 year interval for all eyes $>20 \mathrm{~mm} \mathrm{Hg}$ to be significantly different from the 2.9 years for eyes $>30 \mathrm{~mm} \mathrm{Hg}(p=0.046)$ but the 5.9 year and 3.6 year intervals $(0.317<\mathrm{p}<0.1)$ and the 3.6 year and 2.9 year intervals $(p>0.50)$ were not shown to be significantly different. There is, however, enough evidence to confirm that the trend to a shorter interval for disease progression with higher intraocular pressure is reliable.

Table 4 is constructed to show the comparative rates of progression for treated and untreated glaucoma. The 3.6 year figure for untreated disease from Table 3 (eyes with intraocular pressure $>25 \mathrm{~mm} \mathrm{Hg}$ ) is chosen to provide the most accurate comparison with the data from the Glasgow trial, ${ }^{8}$ which also studied eyes with pressure $>25 \mathrm{~mm} \mathrm{Hg}$ at diagnosis. The data for treated disease are derived from the slope of visual field decay in figure 3 of that paper. Assuming linear progression of field loss with time and in different stages of the disease, the component parts of the slope may be extrapolated to estimate the time taken to progress during treatment from stage 1 field loss to beyond stage 4. During the first year of conventional treatment the group mean visual field deteriorated rapidly while the $30 \%$ of eyes which could not be controlled by medical therapy were identified and submitted to trabeculectomy. Using this part of the slope as an example of unsatisfactory treatment, it would take an average of 10 years to progress from early to end stage disease. After the second year of treatment the condition is more stable, operation is seldom required and the slope of field decay becomes flatter. The deterioration of visual field under these optimum conditions would take about 38 years to reach end stage disease. It is similar to the rate of progression for eyes treated by trabeculectomy at diagnosis. Smith's figure of 33 years for treated glaucoma' is included for comparison.

\section{Discussion}

The results suggest that primary open angle glaucoma can be a more rapidly progressive disease than is recognised. It seems that for pressures over $30 \mathrm{~mm} \mathrm{Hg}$ and after early field defects have appeared, the rest of the visual field may disappear in approximately 3 years or less. Our failure to detect at this pressure level a statistically significant time interval from beginning of field damage to loss of all field, is a failure to detect a time interval significantly different from zero and therefore emphasises the rapidity of possible deterioration. At other pressure levels with longer time intervals for progression, the results are verified statistically and are longer for lower pressures. This cross sectional method of investigation of untreated disease is necessarily indirect as it would be unethical to allow patients to become blind for the purpose a longitudinal study following the progress of an untreated cohort to blindness. The time differences estimated are merely averages without any way of determining individual variation. For example, the 6.5 year progression at pressures between 26 and $30 \mathrm{~mm} \mathrm{Hg}$ is a difference between two means and so it is impossible to calculate the standard deviation necessary to estimate the population scatter. Furthermore, although we have been able to estimate the average effect of different levels of intraocular pressure we cannot find by this method the variation which might be produced by other risk factors such as age, myopia, presence of cardiovascular disease, amount of optic disc cupping, etc. Selection bias caused by the effect of age on the probability of diagnosis, either in the asymptomatic early stage of the disease or in the late stage with visual symptoms, seems unlikely. The results are stratified primarily by the level of intraocular pressure which, for a given stage of field loss, is not likely to be affected by the method of diagnosis.

The study is based on patients whose diagnosis is confirmed after normal hospital referral and, although it includes patients screened for glaucoma when attending their optometrist or an ophthalmology clinic for reasons other than glaucoma, it is not based on comprehensive population screening. We are, however, merely attempting to identify the rate of field loss after the earliest field defects have appeared and need take no account of the period of ocular hypertension which precedes visual field defects. There have been several studies in which the interval before appearance of field defects in ocular hypertension has been related to various risk factors. ${ }^{45}$

Manual rather than automated visual field tests were used in this study. It is unlikely that automated tests would yield different results. The early stage of field loss as we have defined it (stage I) is equivalent to a $30 \mathrm{~dB}$ stimulus on the Humphrey analyser, which would detect minor reductions in sensitivity. The end stage disease, defined as absolute scotomas with $5^{\circ}$ of fixation might equally easily be defined by either manual or automated tests. Indeed, elderly patients with only a tiny central island of vision often fail to complete automated field analysis, a potential source of selection bias.

The relatively long period for disease progression at lower pressure $(14 \cdot 4$ years for pressures between 21 and $25 \mathrm{~mm} \mathrm{Hg})$ is not much different from the 18 year time interval for progression from ocular hypertension to glaucoma described 
by Goldmann. ${ }^{3}$ Thus the level of intraocular pressure in established disease may be more important in predicting outcome than the arbitrary appearance of early field defects. The boundary between ocular hypertension and glaucoma is therefore more a product of our inefficiency in testing vision than an intrinsic change of disease severity. Although we have found the rate of progression to be related to the level of intraocular pressure, this is liable to be a crude approximation. It is likely that the pressure rises gradually during the course of the disease ${ }^{9}$ and so the visual field deterioration may accelerate as the pressure rises. Similarly, as optic disc cupping increases, the remaining nerve fibres may be more vulnerable to damage.

Whatever the approximation inherent in this method of investigation, the untreated disease seems to run a much shorter course than when modified by treatment (see Table 4), and optimum treatment of early disease is likely to preserve useful vision for the lifetime of most patients. The agreement on a possible course for treated disease of just over 30 years found in this study and in Smith's trial' ${ }^{1}$ is reassuring especially as different methods of analysis were used.

It is perhaps possible that some of the deterioration of vision over 30 years is caused by factors other than glaucoma. For example, there is age-related deterioration in the neurosensory component of vision ${ }^{10}$ 11 and increasing density of the crystalline lens will reduce retinal illumination, even before cataract causes visual symptoms. The effect of treated glaucoma by itself may therefore produce a slower change in visual field than the 30 year estimates suggest.

It is important to recognise the possible rapid rate of deterioration when planning the frequency of repeat examination in population screening programmes. Perhaps this should be done after a maximum of 5 years, as some patients may not have a prolonged phase of relatively mild ocular hypertension but may develop dangerously high pressure levels near the beginning of their disease. We are not yet able to assess this possibility. The rapid rate of field loss in untreated disease, especially with pressure over $25 \mathrm{~mm} \mathrm{Hg}$, and the relatively slow deterioration after optimum treatment, emphasises the importance of vigorous treatment.

\section{Summary}

The mean rate of visual field loss in untreated primary open angle glaucoma was estimated by comparing the mean age at presentation of patients with early relative visual field loss with the mean age of those who presented with absolute field loss within five degrees of fixation. Analysis of the records of 177 patients indicated that the rate of field loss was related to the level of untreated intraocular pressure. For pressures of 21 to $25 \mathrm{~mm} \mathrm{Hg}$, untreated disease is likely to progress from early field changes to end stage in an average of 14.4 years. The same interval for pressures of 25 to $30 \mathrm{~mm} \mathrm{Hg}$ was 6.5 years and for pressures over $30 \mathrm{~mm} \mathrm{Hg}, 2.9$ years. For untreated disease at pressures over $25 \mathrm{~mm} \mathrm{Hg}$ the interval is estimated at 3.6 years and this is much shorter than the estimated period of 10 years under imperfect treatment and 38 years under optimum treatment identified in a prospective clinical trial of early trabeculectomy in patients with similar intraocular pressures at diagnosis.

Tennent Institute of Ophthalmology,

JEFFREY L JAY

Wennent Institute of

Church Street,

Glasgow G11 6NT

and

Glasgow Eye Infirmary,

Glasgow G3 7NB

We thank the many consultant colleagues at Glasgow Eye Infirmary and the Tennent Institute who allowed us to examine records of their patients, and Dr Gordon Murray for advice on statistical analysis.

1 Smith RJH. The enigma of primary open angle glaucoma. Trans Ophthalmol Soc UK 1986; 105: 618-33.

2 Mikelberg FS, Schulzer M, Drance SM, Lau W. The rate of progression of scotomas in glaucoma. Am $\mathcal{F}$ Ophthalmol 1986; 101: 1-6.

3 Goldmann H. Some basic problems of simple glaucoma. Am $\mathcal{f}$ Ophthalmo 1959; 48: 213-20.

4 David R, Livingstone DG, Luntz MH. Ocular hypertension: a long term follow up study of treated and untreated patients. Br $\mathcal{F}$ Ophthalmol 1977; 61 . 668-74.

5 Hart WM Jr, Yablonski M, Kass MA, Becker B. Multivariate analysis of the risk of glaucomatous visual field loss. Arch Ophthalmol 1979; 97: 1455-8.

6 Armaly MF, Krueger DE, Maunder L, Becker B, Hetherington J, Kolker AE et at. Biostatistical analysis of the collaborative glaucoma study. 1. Summary of report of the risk factors for glaucomatous visual field defects. Arch Ophthalmol 1980; 98: 2163-71.

7 Jay JL, Murray SB. Early trabeculectomy versus conventional management in primary open angle glaucoma. Br $\mathcal{F}$ Ophthalmol 1988; 72: 881-9.

8 Jay JL, Allan D. The benefit of early trabeculectomy versus conventional management in primary open angle glaucoma relative to severity of disease. Eye 1989; 3: 528-35.

9 Chauhan BC, Drance SM, Douglas GR. The time course of intraocula pressure in timolol treated and untreated glaucoma suspects. Am $\mathcal{f} O \mathrm{ph}-$ thalmol 1989; 107: 471-5.

$10 \mathrm{McGrath} C$, Morrison JD. The effect of age on spatial frequency perception in human subjects. Qf Exp Physiol 1981; 66: 253-61.

11 Jay JL, Mammo RB, Allan D. Effect of age on visual acuity after cataract extraction. Brf Ophthalmol 1987; 71: 112-5. 